\title{
THERMAL CONDUCTIVITY FACTOR FOR BEEF OF NOR AND DFD GRADES AT THE SUBCRYOSCOPIC TEMPERATURES
}

Received 24.06.2021

Received in revised 14.09.2021 Accepted for publication 25.09.2021

\author{
All-Russian Scientific Research Institute of Refrigeration Industry, Moscow, Russia
}

Keywords: thermophysical properties, superchilled, calculation formulas, temperature, humidity, frozen water, meat

\begin{abstract}
Thermal conductivity factor and specific isobaric heat capacity of food products are currently the most important parameters in the development of mathematical models for food freezing and thawing and in improving production technology. There is significant variance among the existing experimental data for the thermal conductivity factor in meat. Most of the modern calculated relationships are based on the nutritional approach, which favorably differs by the ability to calculate the thermophysical characteristics of any food products. However, the calculation error at the subcryoscopic temperatures may be $15 \%$ to $20 \%$. The development of superchilling as a way of storing meat requires high accuracy of freezing time calculation, including vacuumpacked boneless meat. In the presented article, the authors investigated hydrogen index, cryoscopic temperature, frozen moisture proportion and thermal conductivity factor for beef $M$. longissimus dorsi samples of NOR and DFD grades. It was found that DFD beef is characterized by $10 \%$ to $12 \%$ higher values of thermal conductivity factor in comparison with NOR grade. Using the method of regression analysis, the authors developed empirical relationships for calculating the thermal conductivity factor of meat depending on its temperature and $p H$ level. Unlike cryoscopic temperature and frozen moisture proportion, $p H$ is easy to measure and may be easily used on a conveyor belt for more accurate assessment of meat thermophysical properties. With an increase in $\mathrm{pH}$ from 5.3 to 7 , an increase in cryoscopic temperature is observed from minus $0.94{ }^{\circ} \mathrm{C}$ to minus $0.72{ }^{\circ} \mathrm{C}$. It has been shown that one of the factors for the higher cryoscopic temperature and higher $\mathrm{pH}$ level of DFD beef is higher water-holding capacity with less strongly bound moisture.
\end{abstract}

\section{Funding:}

The article was published as part of the research topic foundation for scientific research No. 013.05 of the state assignment of the V. M. Gorbatov Federal Research Center for Food Systems of RAS, topic No. 0585-2019-0043-C-01.

\section{Introduction}

Simulation and control of food refrigeration and heat treatment processes based on the calculation of temperature profiles inside the food product, as well as the determination and justification of points for thermal control are inexorably associated with the need to know the thermophysical properties. Currently, according to the results of studies [1-3], the accuracy of food technology processes simulation is determined primarily by the availability and reliability of the initial data on the thermophysical properties of food products, local heat transfer coefficients, intensity of chemical processes, rather than by the computing power and principles of the numerical models used.

Cooling, freezing and thawing processes are among the main methods of meat preserving [4,5]. In addition, superchilled meat is becoming more common [6]. Superchilling of meat means its surface freezing and subsequent storage at the temperatures $1{ }^{\circ} \mathrm{C}$ to $2{ }^{\circ} \mathrm{C}$ below cryoscopic temperature [7]. According to [8], storing pork at minus $2^{\circ} \mathrm{C}$ instead of plus $3.5^{\circ} \mathrm{C}$ has increased its shelf life from 2 to 16 weeks. The main problem in introducing this technology is to determine the required time of meat freezing, as well as the development of appropriate calculation methods for various linear dimensions of samples and their thermophysical properties [7].

With the introduction of numerical simulation methods for the processes of refrigeration and heat treatment in food industry $[9,10]$, the development of simple and accurate semi-empirical relationships describing the thermophysical properties of meat is of particular importance, including the thermal conductivity factor, which, together with the specific isobaric heat capacity, significantly varies at negative temperatures.

Currently, two methods for determining the thermophysical properties of food products are the most common: calculation based on the nutrient composition [11-13] and the use of experimental data [14-18].

The method for calculating the thermophysical characteristics of products based on the nutrient composition is associated with a higher error, which can be $15 \%$ to $20 \%$, but it may be used for any product. In the ASHRAE handbook [11], data on the composition of products and cryoscopic temperature were obtained empirically (USDA), while the presented thermophysical properties of products were determined by a calculation method based on the thermophysical properties of their nutrients according to the model proposed in [12]. Researchers [12] were among the first 
to obtain and arrange the thermophysical characteristics of individual components in food products (proteins, fats, carbohydrates) in a wide temperature range and developed the corresponding calculation models. In [13], an extensive collection of empirical data from various researches on the nutritional composition of food products and polynomial relationships for calculating their thermophysical properties in the temperature range of minus $40^{\circ} \mathrm{C}$ to plus $40{ }^{\circ} \mathrm{C}$ are presented. Experimental data [14] on the thermal conductivity of beef meat, fat and bones are of special interest.

Experimental studies of the thermal conductivity factor in meat products indicate a significant anisotropy and the effect of its refrigeration and grinding modes on the properties of the product $[19,20]$. A study of the ionizing radiation (dose $12 \mathrm{kGy}$ ) effect on the thermophysical properties of chilled beef and pork [21] showed an increase in the thermal conductivity factor by $15 \%$ to $20 \%$, a decrease in the specific isobaric heat capacity by $10 \%$ to $12 \%$, and a decrease in water activity by $3 \%$. As a possible explanation, the author notes a decrease in the moisture content and water-holding capacity of meat [22].

Considering the product as a multicomponent dispersed medium, three main components may be distinguished for meat, which determine its thermal conductivity factor: muscle fibers (and fat), ice crystals and unfrozen moisture [23]. Attempting to improve approaches for calculating the thermophysical properties of moisture-containing products at subcryoscopic temperatures, the authors [24] noted the need to take into account the structure and size of ice crystals $[25,26]$, as well as to increase the accuracy of the product cryoscopic temperature and the frozen moisture proportion calculations [27].

Research on the thermophysical properties of NOR and DFD beef $[28,29]$ indicated a strong correlation between cryoscopic temperature and meat $\mathrm{pH}$ level. With an increase in the $\mathrm{pH}$ of beef from 5.5 to 6.9 , the cryoscopic temperature increases from minus $1.5^{\circ} \mathrm{C}$ to minus $0.9^{\circ} \mathrm{C}$ [28]. At the temperatures close to cryoscopic temperature, the amount of frozen moisture in meat of different grades may vary by more than $30 \%[29,30,31]$.

Thus, the aim of the presented work is the experimental research and development of a practical approach to the calculation of the thermal conductivity factor in meat of different grades.

\section{Materials and methods}

Measurement of the thermal conductivity factor in beef with the Linseis TNV-100 device equipped with the HotPoint Kapton-foil-sensors (Linseis Messgeraete $\mathrm{GmbH}$, Germany). The metrological characteristics of the device are presented in Table 1 . The stationary temperature mode required for testing was ensured by placing the sensor and the test sample in thermostat with a specified temperature (in the range of plus $20^{\circ} \mathrm{C}$ to minus $35^{\circ} \mathrm{C}$ with a step of $5{ }^{\circ} \mathrm{C}$ ) and holding the sample for at least an hour at a constant temperature recorded by the sensor.

Table 1. Metrological characteristics of the HotPoint sensor by Linseis

$$
\text { Temperature measurement range, }{ }^{\circ} \mathrm{C}
$$

Thermal conductivity measurement range, $\mathrm{W} / \mathrm{m} \cdot \mathrm{K}$ Maximum absolute error when measuring thermal conductivity, \%

Thermal conductivity measurement using the HotPoint sensor is carried out by the method of a non-stationary heat source in the form of a plane. The measuring principle is as follows: the sensor is placed between the two halves of the test sample. During the measurement, a DC current $(10 \mathrm{~mA}, 30 \mathrm{~mW})$ flows through the film resistor of the sensor, causing the temperature to rise. The generated heat is scattered in the sample on both sides of the sensor. The temperature deviation from the initial temperature of the sample measured by the sensor makes it possible to calculate the thermal conductivity of the material under study according to the relationship:

where:

$$
\lambda \approx \frac{Q}{4 \pi \cdot r \cdot \Delta T_{s}}
$$

$Q$ is the heat flow, $\mathrm{W}$;

$r$ is the effective radius of the sensor, $\mathrm{m}$;

$\Delta T_{s}$ is the deviation of the sample temperature from the initial temperature measured by the sensor, ${ }^{\circ} \mathrm{C}$.

The studied beef samples for measuring the thermal conductivity factor were cut in the form of two plates with linear dimensions of at least $40 \mathrm{~mm} \times 40 \mathrm{~mm} \times 10 \mathrm{~mm}$.

The HotPoint sensor was calibrated using reference materials: polymethyl methacrylate (PMMA) (thermal conductivity factor of $0.194 \mathrm{~W} / \mathrm{m} \cdot \mathrm{K}$ ), BK7 optical glass (thermal conductivity factor of $1.118 \mathrm{~W} / \mathrm{m} \cdot \mathrm{K}$ ), and titanium (thermal conductivity factor of $22 \mathrm{~W} / \mathrm{m} \cdot \mathrm{K}$ ). Control measurements of the thermal conductivity in ice and distilled water showed the deviation of the results from the reference values not exceeding $2.5 \%$.

The $\mathrm{pH}$ value of beef was measured using the PCE-228 pH meter (PCE Deutschland GmbH, Germany) characterized by a measurement error not exceeding $\pm 0.5 \%$ at $20{ }^{\circ} \mathrm{C}$.

The moisture content in the samples was measured on the AND ML-50 moisture analyzer by AND Japan, with a sample weight of 5 grams and an error in moisture content measuring not exceeding $0.2 \%$.

The cryoscopic temperature of the samples was measured using the OSKR-1 cryoscope osmometer (KIVI, Russia). This device is equipped with a mechanical initiator of the crystallization process. In the temperature range of $0{ }^{\circ} \mathrm{C}$ to minus $0.93^{\circ} \mathrm{C}$, it provides an error of the cryoscopic temperature measurement not exceeding $\pm 0.002^{\circ} \mathrm{C}$. At the temperatures below minus $0.93^{\circ} \mathrm{C}$, the cryoscopic temperature measurement error is $\pm 0.010{ }^{\circ} \mathrm{C}$.

The amount of frozen moisture in the samples depending on the temperature was measured on the DSC204 F1 
Phoenix $^{\oplus}$ differential scanning calorimeter (NETZSCHGerätebau $\mathrm{GmbH}$, Germany). A detailed description of the methodology for carrying out these measurements and the settings of the device are described in [32]. The error in measuring the enthalpy of phase transitions according to the manufacturer's data does not exceed 3.0\%.

For research, the authors used beef samples of NOR (6 samples) and DFD (6 samples) grades. Samples of beef $M$. longissimus dorsi were obtained at the slaughters of meat processing plants in the Moscow region. For each sample, at least 2 measurements of the thermal conductivity factor, moisture content, cryoscopic temperature and frozen moisture proportion were carried out.

\section{Results and discussion}

According to the studies, the average values of the moisture content in beef of NOR and DFD grades were extremely close and amounted to $\mathrm{W}_{\mathrm{NOR}}=0.762 \pm 0.165$ and $\mathrm{W}_{\mathrm{DFD}}=0.763 \pm 0.011$, respectively, with a confidence level of $p=0.95$. Comparative results of the studies on cryoscopic temperature of samples depending on the $\mathrm{pH}$ values are presented in Figure 1.

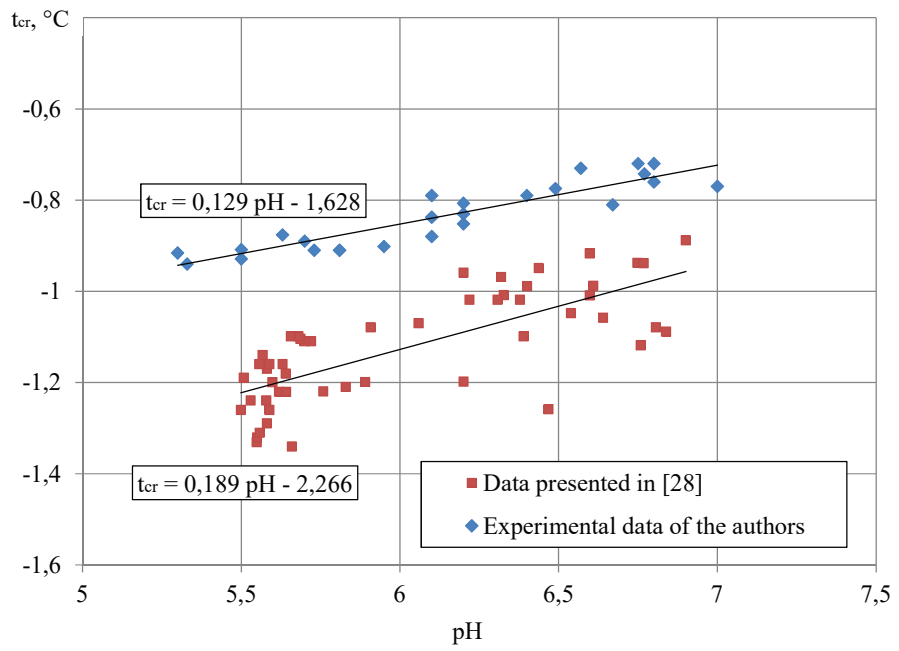

Figure 1. Dependence of the cryoscopic temperatur of $M$. longissimus dorsi on the $\mathrm{pH}$ value

The obtained results are in good agreement with the experimental data obtained by Farouk M. M. et al. in [28]. With an increase in $\mathrm{pH}$ from 5.3 to 7 , an increase in cryoscopic temperature from minus $0.94{ }^{\circ} \mathrm{C}$ to minus $0.72{ }^{\circ} \mathrm{C}$ is observed. At the same time, the cryoscopic temperature of the beef samples studied in this work was on average $0.27^{\circ} \mathrm{C}$ higher than that of Farouk M. M. et al. in [28]. This deviation may be due to both the physical characteristics of specific cattle breeds and the conditions for their feeding and maintenance, which requires additional research beyond the scope of this article. Calculation of the cryoscopic temperature of beef depending on the $\mathrm{pH}$ values may be carried out according to the following relationship:

$$
t_{c r} \approx 0.129 \cdot p H-1.628
$$

Figure 2 shows the dependence of the frozen moisture proportion in the NOR and DFD beef samples obtained with a differential scanning calorimeter, the results obtained by calculation using formula (3), as well as the data presented in [18]. While the moisture content in NOR and DFD samples is equal, the amount of frozen moisture in DFD samples is $1.5 \%$ higher. This confirms the authors' hypothesis [28] that one of the reasons for the higher cryoscopic temperature and $\mathrm{pH}$ value of DFD beef is better water-holding capacity with less strongly bound moisture (by $16 \%$ ).

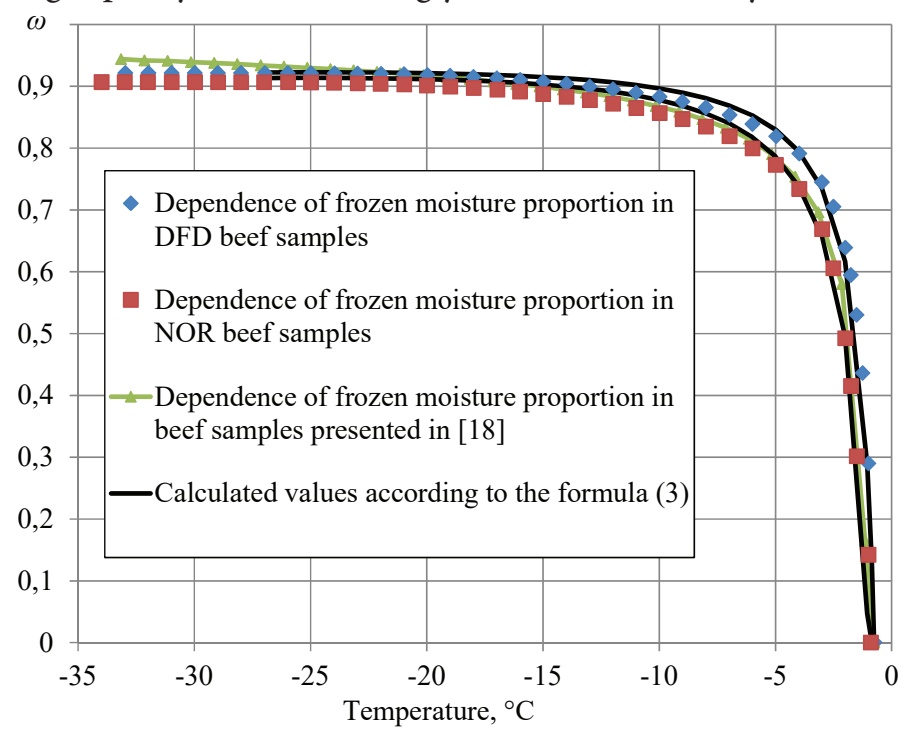

Figure 2. Experimentally determined amount of frozen moisture proportion in meat samples of different grades depending on temperature

The results of the measurements are in satisfactory agreement with the data of V. P. Latyshev [18]. Earlier experiments [30] showed that at temperatures below minus $35^{\circ} \mathrm{C}$, the amount of frozen moisture in meat remains almost unchanged. Taking this into account, a formula was developed for calculating the amount of frozen moisture (3). Its main advantage is the high accuracy of the frozen moisture proportion calculation at the temperatures close to cryoscopic temperature, regardless of the moisture content in the products.

$$
\omega(t, w)=\omega_{f r}(w) \cdot \frac{1-\frac{t_{c r}}{t}-\frac{t_{c r}}{t_{f r}^{2}}\left(t-t_{c r}\right)}{\left[1-\frac{t_{c r}}{t_{f r}}\right]^{2}}
$$

where:

$\omega_{f r}$ is the fraction of freezing water, which depends on the nature of the food product, its moisture content and waterholding capacity,

$t_{f r}$ is the freezing point determined by differential scanning calorimetry on the DSC204 F1 Phoenix ${ }^{\circledast}$ instrument.

The freezing point for most types of meat is minus $33^{\circ} \mathrm{C}$ to minus $35^{\circ} \mathrm{C}$.

The results of experimental studies on thermal conductivity $\lambda$ for beef samples of NOR and DFD grades, in comparison with the data $[14,18]$, determined by the method [24], as well as obtained by calculation according to formulas (4) and (5) are presented in Figure 3. DFD beef is 
$\lambda$,

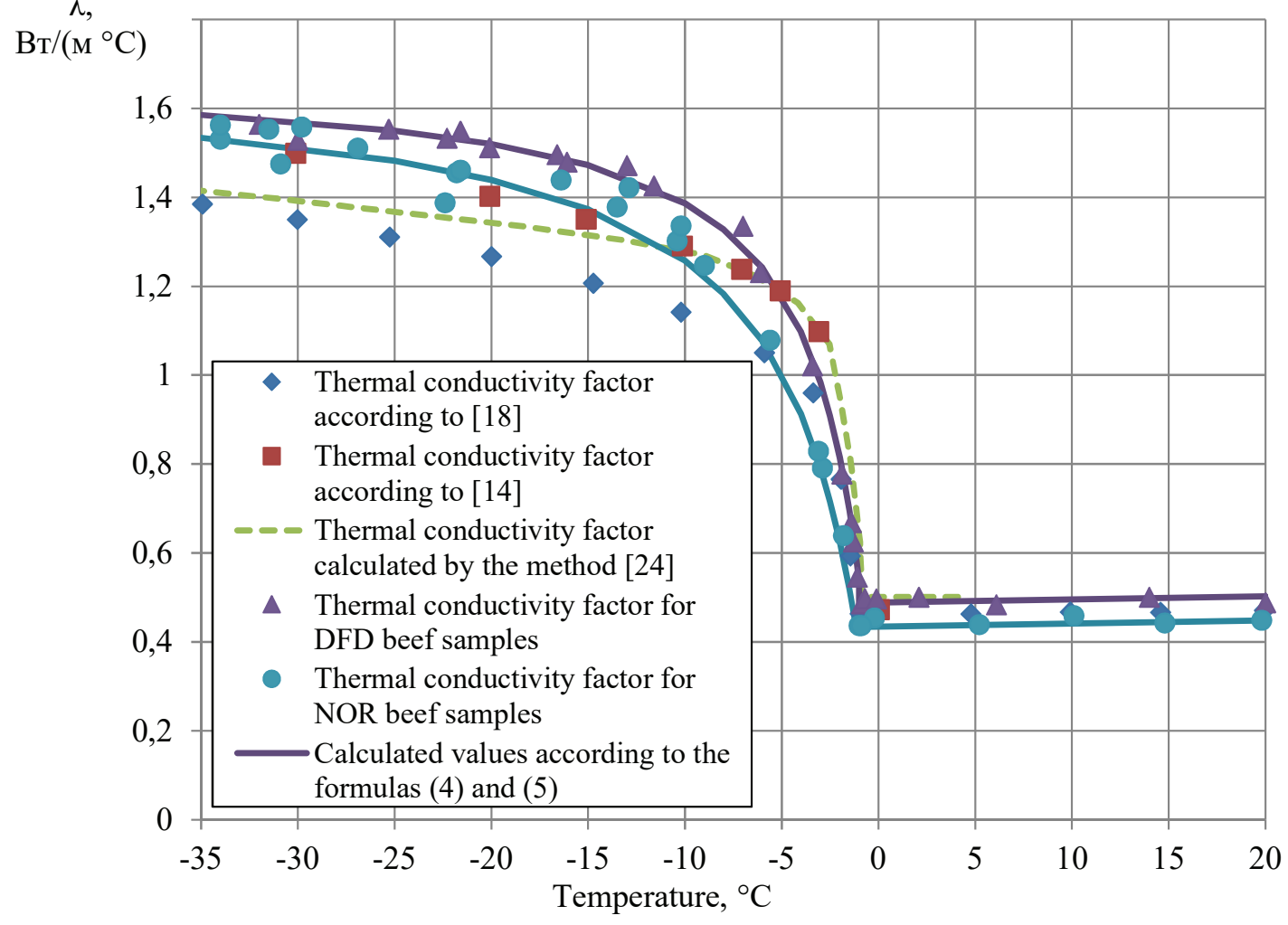

Figure 3. Thermal conductivity factor $\lambda$ for beef of different grades

characterized by $10 \%$ to $12 \%$ higher values of thermal conductivity factor in comparison with NOR beef. Deviations in the thermal conductivity factors of beef obtained in this study, as well as in the works $[14,18]$, may be not only due to different properties of beef samples, but also due to the modes of meat freezing used by the authors. Low chilling rates promote the growth of larger ice crystals and lead to higher thermal conductivity of the samples [26].

For calculating the thermal conductivity factor of beef meat depending on temperature and $\mathrm{pH}$, the authors obtained the following calculated relationship based on the method of regression analysis in the temperature range above cryoscopic temperature:

$$
\lambda(t, p H)=0.26+0.0007 \cdot t+0.0317 \cdot p H
$$

To describe the thermal conductivity factor in the temperature range below cryoscopic temperature, the authors initially attempted to develop a semi-analytical relationship taking into account relationships (2) and (3), but the coefficient of the experimental data determination was very low and did not exceed 0.7 . As a result, preference was given to the development of an empirical relationship and the regression analysis:

$$
\lambda(t, p H)=\frac{t}{0.595 \cdot t+0.435 \cdot p H-4.398}
$$

The proposed relationship describes the data collected by the authors on the thermal conductivity of beef at temperatures below cryoscopic temperature with determination coefficient $\mathrm{R}^{2}=0.95$. The choice of $\mathrm{pH}$ as one of the variables is primarily based on the simplicity of its measurements, in contrast to the cryoscopic temperature. These relationships are aimed primarily at the development of rapid numerical methods for determining the required duration of freezing for vacuum-packed boneless meat and improving conveyor technologies for meat superchilling.

\section{Conclusion}

With the introduction of superchilling technology for vacuum-packed boneless meat, the development of mathematical models for the process of its freezing, as well as obtaining relationships to describe its thermophysical properties, become more relevant than ever. The $\mathrm{pH}$ value is easy to measure and, unlike cryoscopic temperature, may be easily used in conveyor production for a more accurate assessment of meat thermophysical properties.

With an increase in $\mathrm{pH}$ from 5.3 to 7 , an increase in cryoscopic temperature is observed from minus $0.94{ }^{\circ} \mathrm{C}$ to minus $0.72{ }^{\circ} \mathrm{C}$. Frozen moisture proportion analysis was confirmed by other authors showing that one of the reasons for the higher cryoscopic temperature and $\mathrm{pH}$ of DFD beef is higher water holding capacity with less strongly bound moisture.

For meat of different grades, there is a difference in the values of thermal conductivity by $10 \%$ to $12 \%$. The authors have developed empirical relationships for calculating the thermal conductivity factor of meat depending on temperature and $\mathrm{pH}$ value. 


\section{REFERENCES}

1. Datta, A. K. (2007). Porous media approaches to studying simultaneous heat and mass transfer in food processes. I: Problem formulations. Journal of Food Engineering, 80(1), 80-95. https://doi.org/10.1016/j.jfoodeng.2006.05.013

2. Datta, A. K. (2007). Porous media approaches to studying simultaneous heat and mass transfer in food processes. II: Property data and representative results. Journal of Food Engineering, 80(1), 96-110. https://doi.org/10.1016/j.jfoodeng.2006.05.012

3. Kuffi, K. D., Defraeye, T., Nicolai, B. M., De Smet, S., Geeraerd, A., Verboven, P. (2016). CFD modeling of industrial cooling of large beef carcasses. [Modélisation par la mécanique numérique des fluides du refroidissement industriel de grandes carcasses de bœuf] International Journal of Refrigeration, 69, 324-339. https://doi.org/10.1016/j.ijrefrig.2016.06.013

4. Klettner, P. -G. (1996). Cooling and freezing of carcasses Fleischwirtschaft, 76(7), 679-687. (In German)

5. Zhou, G. H., Xu, X. L., Liu, Y. (2010). Preservation technologies for fresh meat-A review. Meat science, 86 (1), 119-128. https://doi.org/10.1016/j.meatsci.2010.04.033

6. Kaale, L. D., Eikevik, T. M., Rustad, T., Kolsaker, K. (2011). Superchilling of food: A review. Journal of Food Engineering, 107(2), 141-146. https://doi.org/10.1016/j.jfoodeng.2011.06.004

7. Magnussen, O. M., Haugland, A., Torstveit Hemmingsen, A. K., Johansen, S., Nordtvedt, T. S. (2008). Advances in superchilling of food - process characteristics and product quality. Trends in Food Science and Technology, 19(8), 418-424. https://doi. org/10.1016/j.tifs.2008.04.005

8. Duun, A. S., Hemmingsen, A. K. T., Haugland, A., Rustad, T. (2008). Quality changes during superchilled storage of pork roast. LWT - Food Science and Technology, 41(10), 2136-2143. https://doi.org/10.1016/j.lwt.2008.02.001

9. Cevik, M., Icier, F. (2021). Numerical simulation of temperature histories of frozen minced meat having different fat contents during ohmic thawing. International Journal of Thermal Sciences, 165, Article 106958. https://doi.org/10.1016/j.ijthermalsci.2021.106958

10. Zhao, Y., Takhar, P. S. (2017). Freezing of foods: Mathematical and experimental aspects. Food Engineering Reviews, 9, 1-12. https://doi.org/10.1007/s12393-016-9157-z

11. ASHRAE (2018). Ultralow-Temperature Refrigeration. Chapter in a book: ASHRAE. Handbook. Refrigeration. Atlanta, USA, 2018.

12. Choi Y. (1987). Effects of temperature and composition on the thermal conductivity and thermal diffusivity of some food components. Korean Journal of Food Science and Technology, 18(5), 357-353.

13. Amos, N. D., Willix, J., Chadderton, T., North, M. F. (2008). A compilation of correlation parameters for predicting the enthalpy and thermal conductivity of solid foods within the temperature range of $-40{ }^{\circ} \mathrm{C}$ to $+40{ }^{\circ} \mathrm{C}$. International Journal of Refrigeration, 31(7), 1293-1298. https://doi.org/10.1016/j.ijrefrig.2008.01.011

14. Willix, J., Lovatt, S. J., Amos, N. D. (1998). Additional thermal conductivity values of foods measured by a guarded hot plate. Journal of Food Engineering, 37(2), 159-174. https://doi. org/10.1016/S0260-8774(98)00086-7

15. Pham, Q. T., Willix, J. (1989). Thermal conductivity of fresh lamb meat, offals and fat in the range -40 to $+30^{\circ} \mathrm{C}$ : Measurements and correlations. Journal of Food Science, 54(3), 508-515. https://doi.org/10.1111/j.1365-2621.1989.tb04639.x

16. Sanz Martínez, P. D., Alonso, M. D., Mascheroni, R. H. (1987). Thermophysical properties of meat products: General bibliography and experimental values. Transactions - American Society of Agricultural Engineers: General Edition, 30(1), 283-290. https://doi.org/10.13031/2013.30441

17. Sweat, V. E., Haugh, C. G., Stadelman, W. J. (1973). Conductivity of chicken meat at temperatures between -75 and $20^{\circ}$ C. Food Science, 38(1), 158-160. https://doi.org/10.1111/j.1365-2621.1973. tb02802.x
18. Latyshev, V.P. (1992). Recommended References for Thermal Calculations of Foods. Moscow: Agroholodprom, 1992. (In Russian)

19. Elansari, A. M., Hobani, A. I. (2009). Effect of temperature and moisture content on thermal conductivity of four types of meat. International Journal of Food Properties, 12(2). 308-315. https://doi.org/10.1080/10942910701687519

20. Lind, I. (1991). The measurement and prediction of thermal properties of food during freezing and thawing - a review with particular reference to meat and dough. Journal of Food Engineering, 13(4), 285-319. https://doi.org/10.1016/02608774(91)90048-W

21. Timakova, R. T. (2019). Comparative characteristics of the technological properties of radiation-processed raw meat. Food industry, 9, 8-12. https://doi.org/10.24411/0235-24862019-10136 (In Russian)

22. Svetlov, Yu. V., Nikiforov, Yu. B. (2015). Effective thermal conductivity and inner transfer surface of porous and fibrous materials on the example of foodstuffs. Fine Chemical Technologies, 10(6), 71-78. (In Russian)

23. Tarnawski, V. R., Cleland, D. J., Corasaniti, S., Gori, F., Mascheroni, R. H. (2005). Extension of soil thermal conductivity models to frozen meats with low and high fat content. International Journal of Refrigeration, 28(6), 840-850. https://doi.org/10.1016/j. ijrefrig.2005.01.012

24. Van der Sman, R. G. M. (2008). Prediction of enthalpy and thermal conductivity of frozen meat and fish products from composition data. Journal of Food Engineering, 84(3), 400-412. https://doi.org/10.1016/j.jfoodeng.2007.05.034

25. Do, G. -S., Sagara, Y., Tabata, M., Kudoh, K. -I., Higuchi, T. (2004). Three-dimensional measurement of ice crystals in frozen beef with a micro-slicer image processing system. International Journal of Refrigeration, 27(2), 184-190. https://doi. org/10.1016/S0140-7007(03)00042-2

26. Van Der Sman, R. G. M., Voda, A., Van Dalen, G., Duijster, A. (2013). Ice crystal interspacing in frozen foods. Journal of Food Engineering, 116(2), 622-626. http://doi.org/10.1016/j. jfoodeng.2012.12.045

27. Van der Sman, R. G. M., Boer, E. (2005). Predicting the initial freezing point and water activity of meat products from composition data. Journal of Food Engineering, 66(4), 469-475. https://doi.org/10.1016/j.jfoodeng.2004.04.018

28. Farouk, M. M., Kemp, R. M., Cartwright, S., North, M. (2013). The initial freezing point temperature of beef rises with the rise in pH: A short communication. Meat Science, 94(1), 121-124. https://doi.org/10.1016/j.meatsci.2012.12.018

29. Dibirasulaev, M.A., Belozerov, G. A., Arkhipov, L.0., Dibirasulaev, D.M., Donenskikh, A.G. (2017). Towards the development of scientifically substantiated modes of cold storage of meat of various quality groups at subcryoscopic temperatures. Poultry and Poultry Products, 1, 29-32. (In Russian)

30. Berezovsky Yu.M., Korolev, I.A., Agafonkina, I.V., Sarantsev, T.A. (2018). Investigation of the effect of beef moisture content on the amount of bound moisture with the calorimetric method. Proceedings of the Voronezh State University of Engineering Technologies, 80(4(78)), 25-29. https://doi.org/10.20914/23101202-2018-4-25-29 (In Russian)

31. Belozerov, G. A., Berezovskiy, Y. M., Korolev, I. A., Sarantsev, T. A. (2020). A calculation model for the heat capacity of beef with different moisture during freezing taking into account free water crystallization. Theory and practice of meat processing, 5(4), 2934. https://doi.org/10.21323/2414-438X-2020-5-4-29-34

32. Belozerov, A. G., Berezovsky, Y. M., Zherdev, A. A., Korolev, I. A., Pushkarev, A. V., Agafonkina, I. V., Tsiganov, D. I. (2018). A study of the thermophysical properties of human prostate tumor tissues in the temperature range from- 160 to $+40{ }^{\circ} \mathrm{C}$. Biophysics (Russian Federation), 63(2), 268-273. https://doi.org/10.1134/ S0006350918020057 


\section{AUTHOR INFORMATION}

Yuri M. Berezovsky - doctor of technical sciences, the head of the laboratory, research laboratory of Food Products Thermophysical Properties, All-Russian Research Institute of the Refrigeration Industry. 12, Kostyakova str., 127422, Moscow, Russia. Tel.: +7-909-685-49-83, E-mail: birjuza1@mail.ru

ORCID: https://orcid.org/0000-0003-1002-2580

* corresponding author

Igor A. Korolev - candidate of technical sciences, researcher, research laboratory of Food Products Thermophysical Properties, All-Russian Research Institute of the Refrigeration Industry. 12, Kostyakova str., 127422, Moscow, Russia. Tel.: +7-916-423-42-17, E-mail: korolev.vnihi@ mail.ru

ORCID: https://orcid.org/0000-0003-3166-2827

Taras A. Sarantsev - research engineer, research laboratory of Food Products Thermophysical Properties, All-Russian Research Institute of the Refrigeration Industry. 12, Kostyakova str., 127422, Moscow, Russia. Tel.: +7-915-282-18-24, E-mail: codyjeps@gmail.com ORCID: https://orcid.org/0000-0001-9755-3047

All authors are responsible for the work and data presented.

All authors made an equal contribution to the work.

The authors were equally involved in writing the manuscript and are equally responsible for plagiarism.

The authors declare no conflict of interest. 